\title{
Sensibilidade a Antimicrobianos e Produção de ESBL por Salmonella sp. Isoladas de Salas de Cortes de Plantas Processadoras de Aves do Oeste Paranaense
}

\author{
Rosangela Estel Ziech (I), Camila Lampugnani (I), Ana Paula Perin \\ (I), Mallu Jagnow Sereno (I), Ricardo Antônio Pilegi Sfaciotte (I), \\ Cibeli Viana (I), Luciano dos Santos Bersot (I)
}
(I) UFPR - Universidade Federal do Paraná - Setor Palotina (Rua Pioneiro, 2153, Bairro Jardim Dallas, Palotina, PR)

\section{Resumo}

A alta prevalência de estirpes de Salmonella sp. resistentes a antimicrobianos isoladas de alimentos de origem animal tem sido relatada no mundo inteiro. Embora exista uma variedade de mecanismos, um dos maiores problemas descritos em enterobactérias é a resistência a betalactâmicos, especialmente a produção de beta lactamase de espectro estendido (ESBL). Dessa forma, o objetivo deste estudo foi pesquisar a sensibilidade de Salmonella sp. frente a antimicrobianos e a prevalência de estirpes produtoras de ESBL isoladas de esteiras condutoras de cortes de frango em plantas processadoras de aves no oeste do PR. Foram utilizadas 98 estirpes de Salmonella sp. oriundas de salas de cortes de quatro diferentes plantas de processamento de aves. Para o teste de suscetibilidade aos antimicrobianos, pelo método de difusão de disco, foram utilizados 18 agentes de 9 classes distintas: ampicilina, cefaclor, ceftiofur, estreptomicina, tobramicina, gentamicina, amicacina, neomicina, enrofloxacina, ácido nalidíxico, ciprofloxacina, florfenicol, sulfa/trimetoprim, tetraciclina, cloranfenicol, meropenem, imipenem e polimixina B. A produção de ESBL foi avaliada pelo método de discodifusão dupla. Como controle de qualidade foi utilizada a E. coli ATCC 25922. O índice de resistência múltipla aos antimicrobianos (IRMA) foi calculado pela razão entre o número de classes contra as quais cada isolado

\footnotetext{
Referência:

Rosangela Estel Ziech, Camila Lampugnani, Ana Paula Perin, Mallu Jagnow Sereno, Ricardo Antônio Pilegi Sfaciotte, Cibeli Viana, Luciano dos Santos Bersot. Sensibilidade A Antimicrobianos e Produção de Esbl por Salmonella Sp. Isoladas de Salas de Cortes de Plantas Processadoras de Aves do Oeste Paranaense. In: Anais do 12 Congresso Latinoamericano de Microbiologia e Higiene de Alimentos - MICROAL 2014 [= Blucher Food Science Proceedings, num.1, vol.1]. São Paulo: Editora Blucher, 2014. DOI 10.5151/foodsci-microal-273
} 
foi resistente e o número total de classes. Das 98 estirpes testadas, 95 apresentaram resistência a pelo menos uma classe antimicrobiana e 84 a mais de 3 classes (IRMA acima de 0,3). Os maiores índices de resistência foram frente ao ácido nalidíxico (95\%), à tetraciclina (91\%), aos betalactâmicos ampicilina e cefaclor (45\%), seguidos pelos aminoglicosídeos estreptomicina e gentamicina com 19\% e 15\%, respectivamente. Em contrapartida, $97 \%$ das estirpes foram sensíveis ao cloranfenicol, um dos primeiros fármacos utilizados na veterinária, de uso proibido em animais desde 1998. Quando observada a produção da enzima ESBL, 45\% das estirpes mostraram-se produtoras pelo método utilizado. As altas taxas de resistência aos antimicrobianos e produção de ESBL observadas neste estudo atentam para a emergência de estirpes multirresistentes e a necessidade do uso prudente de antimicrobianos.

Palavras-Chave: esteiras condutoras de cortes de frango, patógenos alimentares, resistência antimicrobiana

\section{Agência de Fomento:}

